\title{
EDITORIAL \\ London 1935: the frontal lobe, insanity, and a brain surgery
}

\author{
Mark C. Preul, MD, ${ }^{1}$ and T. Forcht Dagi, MD, DMedSc, DHC ${ }^{2}$ \\ 1Department of Neurosurgery, Barrow Neurological Institute, St. Joseph's Hospital and Medical Center, Phoenix, Arizona; and \\ ${ }^{2}$ The School of Medicine, Dentistry and Biomedical Sciences, Queen's University Belfast, Northern Ireland, United Kingdom
}

$\mathrm{F}$ RONTAL leucotomy for psychiatric disease was first proposed by António Egas Moniz (1874-1955) in what is often described as an epiphany that took place at the Second International Neurological Congress of London in 1935 after John Fulton, the preeminent Yale neuroscientist, and his colleague Carlyle Jacobsen presented 2 chimpanzees with attenuated frustration behavior after frontal lobotomy. It is quite likely, however, that this account is mythologized, and that Moniz had actually been thinking about this for some time based on exist-

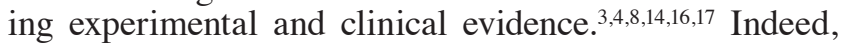
Moniz claimed to have discussed the idea with the neurosurgeon Pedro Almeida Lima as early as $1933 .{ }^{1}$ Although there seems little question that Moniz and Fulton conferred at the Congress, Fulton also disputed the account of a sudden intuition. Indeed, there was intense interest in the function of the frontal lobes throughout the early 20th century, and a number of neurosurgeons in various countries had considered the prospect of frontal lobe surgery well before the Congress. ${ }^{7,8}$

Authors Lillian Boettcher and Dr. Sarah Menacho present a wonderful read in this Neurosurgical Focus issue that describes the scientific milieu and environment of the "collision" between science and brain surgery management proposed for the mentally ill. ${ }^{2}$ Their paper focuses on a world event, the 1935 International Neurological Congress in London, which hosted a special session on the frontal lobe, with New York neurologist Bernard Sachs having chaired the session-planning group. The session brought together luminaries in neurological science, psychiatry, and neurosurgery. Reading like a "Who's Who" of brain science, the session included Egas Moniz, John Fulton, Carlyle Jacobsen, Richard Brickner, Wilder Penfield, Henri Claude, and Clovis Vincent, among others. Boettcher and Menacho describe what seems to be a more evolutionary experience for Moniz to confirm the application of his theory toward a procedure.
It cannot be verified whether Moniz had discussions with Fulton or others at the sessions, although the clinical surgical work of Dandy's case presented by Brickner appears to have most impressed Moniz. That patient was one of the first to undergo systematic postsurgery neuropsychological testing. Certainly such testing and investigation, including an incredible number of patients who had been intraoperatively studied and who had undergone brain mapping, was well under way by 1935 and reached its early peak with Penfield. The mystery lies in how Moniz became convinced to do such a procedure when he really had little if any specialized background in the thencurrent and more modern concepts of experimental neuroscience and scientific surgery exemplified by Fulton and Penfield, respectively. Nobody at that time had done more cortical mapping and select brain resection than Penfield, who had also done bilateral symmetrical removals of cortex along fissure lines to leave behind "normally" functioning gyri (gyrectomy). Penfield believed that lobotomy was more annoying than debilitating; he pointed out some years later the severe defects in planning and initiative after removal of the frontal association area. Moniz hastened to publish his experience, which he considered successful; he published a monograph regarding it in $1936 . .^{15}$ Follow-up was rudimentary. Postoperative complications as well as cognitive changes were reported for each patient. One-third were reported significantly improved, one-third somewhat improved, and one-third unchanged.

On the one hand, the initial adoption of this procedure was driven by a series of converging neuroanatomical, neurophysiological, and behavioral observations, all of which seemed highly exhilarating. There was also an explosion of interest in psychiatric disease by neurologists and other neurosurgeons., ${ }^{910,13,17}$ Lobotomy held forth the prospect of curing psychiatric disease-a huge social problem for which no good treatment options were available at the time. It also offered an alternative to the 
therapeutic nihilism of the century before, and a calmer complement to violent insulin shock, electroshock, straitjackets, ice baths, and restraints, some of which had recently been introduced and some of which were left over from centuries before. The side effects of the sedatives then available were often dire. Lobotomy was an improvement over the squalor of mistreatment and the self-torture of a mental asylum. Although patients were rendered apathetic, families might even be able to take their loved ones home and manage them in some way, as they were freed from their previous behavioral rages.

On the other hand, Moniz's initial reports were greeted with some hostility. He was accused of creating a "cerebral mythology" inasmuch as the pathophysiology of depression, anxiety, and psychosis, and their early indications, were not understood. ${ }^{10,12}$ Although it is sometimes said that lobotomy "spread like wildfire," that is probably an unwarranted exaggeration. ${ }^{6}$ In fact, with the exception of Italy, where more than 200 leucotomies had been carried out by 1939, adoption in Europe was relatively slow. Only 6 had been performed in Great Britain before 1942. ${ }^{11}$ Had Moniz not already been admired for his work on cerebral angiography and for other political and educational accomplishments, resistance to leucotomy may well have been pronounced. Moniz put "psychosurgery" on the track where it would reach its zenith and infamous reputation with Walter Freeman, with some 100,000 such surgeries accounted for worldwide by an editorial in the British Medical Journal in $1971 .{ }^{5}$

Although Moniz was the 1949 Nobel Laureate in Physiology or Medicine for his discovery of the therapeutic value of leucotomy in certain psychoses, this story reaches the state of the incredible, with a procedure that had once been medically accepted becoming viewed in the 1950s and 1960s with increasing skepticism and doubt, and even as horrific by some. The impact on our attitudes toward mental illness and those behaviorally or sociologically at risk is central to this history, without even mentioning frontal lobotomy applied to patients with intractable pain. As the famed neurosurgeon Penfield once said to Freeman in the early years of lobotomy: "Walter, don't you realize that you're doing a very dangerous thing?" Boettcher and Menacho describe a seminal meeting with its implications at the beginning of a significant history that becomes mesmerizing, gripping, fascinating, and stomach-churning with every turn.

https://thejns.org/doi/abs/10.3171/2017.6.FOCUS17429

\section{References}

1. Berrios GE: The origins of psychosurgery: Shaw, Burckhardt and Moniz. Hist Psychiatry 8:61-81, 1997

2. Boettcher LB, Menacho ST: The early argument for prefrontal leucotomy: the collision of frontal lobe theory and psychosurgery at the 1935 International Neurological Congress in London. Neurosurg Focus 43(3):E4, 2017

3. Braslow J: Therapeutic effectiveness and social context: the case of lobotomy in a California state hospital, 1947-1954. West J Med 170:293-296, 1999

4. Braslow JT: Mental Ills and Bodily Cures: Psychiatric Treatment in the First Half of the Twentieth Century. Berkeley: University of California Press, 1997

5. British Medical Journal: Modified prefrontal leucotomy. Br Med J 3:595-596, 1971

6. Eljamel S: Legal issues in behavioural surgery, in Sun B, De Salles A (eds): Neurosurgical Treatments for Psychiatric Disorders. Dordrecht: Springer, 2015

7. Feldman RP, Goodrich JT: Psychosurgery: a historical overview. Neurosurgery 48:647-659, 2001

8. Gross D, Schäfer G: Egas Moniz (1874-1955) and the "invention" of modern psychosurgery: a historical and ethical reanalysis under special consideration of Portuguese original sources. Neurosurg Focus 30(2):E8, 2011

9. Heller AC, Amar AP, Liu CY, Apuzzo ML: Surgery of the mind and mood: a mosaic of issues in time and evolution. Neurosurgery 59:720-739, 2006

10. Kotowicz Z: Gottlieb Burckhardt and Egas Moniz-two beginnings of psychosurgery. Gesnerus 62:77-101, 2005

11. Kotowicz Z: Psychosurgery in Italy, 1936-39. Hist Psychiatry 19:476-489, 2008

12. Lieberman JA, Ogas O: Shrinks: The Untold Story of Psychiatry. Boston: Little, Brown \& Co, 2015

13. Mashour GA, Walker EE, Martuza RL: Psychosurgery: past, present, and future. Brain Res Brain Res Rev 48:409-419, 2005

14. Moniz E: Prefrontal leucotomy in the treatment of mental disorders. 1937. Am J Psychiatry 151 (6 Suppl):236-239, 1994

15. Moniz E: Tentative opératoires dans le traitement de certaines psychoses. Paris: Masson \& Cie, 1936

16. Swayze VW II: Frontal leukotomy and related psychosurgical procedures in the era before antipsychotics (1935-1954): a historical overview. Am J Psychiatry 152:505-515, 1995

17. Valenstein ES: Great and Desperate Cures. New York: Basic Books, 1986

\section{Disclosures}

The authors report no conflict of interest. 